\title{
Profile of English salaried GPs: labour mobility and practice performance
}

\author{
Alexander Ding, Mark Hann and Bonnie Sibbald
}

\begin{abstract}
Background

Recent national policy changes have provided greater flexibility in GPs' contracts. One such policy is salaried employment, which offers reduced hours and freedom from out-of-hours and administrative responsibilities, aimed at improving recruitment and retention in a labour market facing regional shortages.
\end{abstract}

Aim

To profile salaried GPs and assess their mobility within the labour market.

Design of study

Serial cross-sectional study.

Setting

All GPs practising in England during the years 1996/1997, 2000/2001, and 2004/2005.

\section{Method}

Descriptive analyses, logistic regression.

Results

Salaried GPs tended to be either younger ( $<35$ years) or older ( $\geq 65$ years), female, or overseas-qualified; they favoured part-time working and personal medical services contracts. Salaried GPs were more mobile than GP principals, and have become increasingly so, despite a trend towards reduced overall mobility in the GP workforce. Practices with salaried GPs scored more Quality and Outcomes Framework points and were located in slightly more affluent areas.

\section{Conclusion}

Salaried status appears to have reduced limitations in the labour market, leading to better workforce deployment from a GP's perspective. However, there is no evidence to suggest it has relieved inequalities in GP distribution.

\section{Keywords}

career mobility; England; general practitioners; health manpower; primary health care.

\section{INTRODUCTION}

English GPs are traditionally self-employed contractors, known as principals. They provide a standard set of general medical services, under a nationally agreed contract, to the NHS. Recent national policy changes, including the NHS (Primary Care) Act 1997, and the new general medical services (GMS) contract of 2004, ${ }^{1}$ have provided greater working flexibility for GPs. Such flexibilities include locally-agreed contracts - also known as personal medical services (PMS) contracts ${ }^{2}-$ and contracts afforded to entire general practice partnerships, rather than individual GPs. These changes have created a vast expansion in salaried employment opportunities.

Policy makers anticipated that greater flexibility would improve GP recruitment and retention, and quality of care, particularly in deprived areas. ${ }^{3}$ However, research to date has been inconclusive in this respect. Williams et al observed only modest improvements in recruitment of GPs into deprived areas with the first wave of salaried GPs, ${ }^{4}$ while Gosden et al found no statistically significant improvement in quality of care or change in GP behaviour (for example, hours worked and workload composition, consultation length, prescribing/referral rates) resulting from switching to salaried payment. ${ }^{5}$

It was hypothesised that salaried GPs may provide better quality of care as a result of their lack of administrative duties or financial incentives to increase their patient list size and reduce the

\footnotetext{
A Ding, MD, MS, house officer, School of Medicine, University of California San Francisco, California, US. M Hann, PhD, statistician; B Sibbald, PhD, professor of health services research, National Primary Care Research and Development Centre, University of Manchester, Manchester, UK.

Address for correspondence

Dr Hann, NPCRDC, 5th Floor, Williamson Building, University of Manchester, Oxford Road, Manchester, M13 9PL. E-mail: mark.hann@manchester.ac.uk.

Submitted: 19 June 2007; Editor's response: 24 July 2007; final acceptance: 26 September 2007.

(c)British Journal of General Practice 2008; 58: 20-25. DOI: 10.3399/bjgp08X263776
} 
number of patient consultations. Salaried status also imparts other advantages, such as income stability, greater flexibility with geography and schedule, and no financial stake or risk in practice ownership. ${ }^{6}$ Disadvantages include lower income, perceived lower status, and a shorter-term contract. Nevertheless, Gosden et al found that overall levels of job satisfaction in salaried and principal GPs were similar, while salaried GPs reported lower stress. ${ }^{7}$

This paper expands on the limited research into salaried GPs in the UK, nearly a decade after the introduction of salaried posts. The study provides insight into the present characteristics of salaried GPs, determines their mobility, and investigates whether salaried status is associated with practice performance.

\section{METHOD}

This cross-sectional study used GMS and PMS data (the GP census) available from The Information Centre, which annually records all practising GPs in England. Statistical analysis was performed in STATA (version 9).

\section{Profiling salaried and principal GPs}

Salaried GPs were defined as any GP labelled as an assistant, salaried, retainer, or other; registrars were excluded as they are GPs in training. Using 2005 GP census data, as it was the most recently available at the time of the study, demographic, and geographic characteristics of the GPs were tabulated by salaried versus principal status. Available characteristics were age $(25-34,35-44,45-54$, 55-64, $\geq 65$ years), sex, time commitment (fulltime/part-time), type of contract (GMS/PMS), country of primary medical qualification (UK, European Economic Area, or rest of the world), and UK region of current employment.

Logistic regression was then performed to determine which characteristics were most strongly associated with salaried status. As there was no wider reference population to which the data could be generalised, formal significance testing is highly contentious: in such a large dataset, all associations are likely to be highly significant. Therefore, this study simply examined the magnitude of the associations with salaried status in terms of adjusted odds ratios (ORs) and their 95\% confidence intervals (95\% Cls).

\section{GP mobility}

To assess GP mobility, health geographies were compared in two adjacent years (2004 and 2005) at practice level. GPs entering or leaving the workforce between censuses were excluded. GPs remaining in the workforce were 'tracked' using their unique

\section{How this fits in}

Salaried GP posts introduced in the late 1990s were expected to improve

labour mobility and reduce inequalities in distribution. Initial studies suggested

that salaried posts were targeted to under-served areas, and generally filled by

younger men. Salaried GPs were cited as providing higher quality care. This

paper investigates these claims nearly a decade after the introduction of

salaried GP posts. Findings revealed that salaried posts were now more likely to

be filled by female than male GPs, and that such positions remained popular

with younger GPs. Further research is required to determine whether there is an association between salaried status and practice performance.

General Medical Council identifiers. Mobility was identified as a change in practice code between years, and was initially cross-tabulated by salaried/principal status. Logistic regression was then used to determine whether age, sex, time commitment, contract type, and country of qualification were confounders of the relationship between mobility and salaried/principal status. Additionally, it was noted whether GPs changed their salaried or principal status from year to year.

In an attempt to determine whether GP mobility had increased or declined in recent years, crosstabulations were repeated for 1996/1997 and $2000 / 2001$. Continuing changes in health geography and identification codes made it very difficult to construct a continuous series.

\section{Practice performance and deprivation}

To investigate if practice performance was associated with salaried status, a measure of

Table 1. Summary of GP characteristics 2005.

\begin{tabular}{lccc} 
Characteristic & $\begin{array}{c}\text { Salaried GPs } \\
(n=4040)\end{array}$ & $\begin{array}{c}\text { Principal GPs } \\
(n=29340)\end{array}$ & $\begin{array}{c}\text { All GPs } \\
(n=33380)\end{array}$ \\
\hline Age, years: mean (SD) & $41(10.47)$ & $47(9.05)$ & $46(9.41)$ \\
\hline $\begin{array}{l}\text { Sex, } n \text { (\%) } \\
\text { Males }\end{array}$ & $1190(29)$ & $18437(63)$ & $19627(59)$ \\
Females & $2850(71)$ & $10903(37)$ & $13753(41)$ \\
\hline FTE, mean & 0.7 & 0.9 & 0.88 \\
\hline FT/PT status, $n(\%)$ & $1450(36)$ & $22563(77)$ & $24013(72)$ \\
FT & $2590(64)$ & $6777(23)$ & $9367(28)$ \\
PT & & & \\
Country of qualification, $n(\%)$ & $3182(79)$ & $23781(81)$ & $26963(81)$ \\
UK & $321(8)$ & $1324(5)$ & $1645(5)$ \\
EEA & $537(13)$ & $4233(14)$ & $4770(14)$ \\
RoW & & & \\
GMS/PMS contract, $n(\%)$ & $2440(60)$ & $19528(67)$ & $21968(66)$ \\
GMS & $1600(40)$ & $9812(33)$ & $11412(34)$ \\
PMS
\end{tabular}

$F T E=$ full-time equivalence. $F T=$ full-time. $P T=$ part-time. $E E A=$ European Economic Area. RoW = rest of world. GMS = general medical services. $P M S=$ personal medical services. 
'salariedness' was generated, defined as the number of full-time equivalent salaried positions per 1000 practice population. GP registrars were included here as their presence is associated with larger list sizes. Posts that were attached to primary care trusts, and not individual practices, were excluded from the analysis.

It was subsequently discovered that the majority of practices did not employ a salaried GP, and it was therefore decided to redefine the measure of salariedness to 'practice employs a salaried GP or not'. Performance was defined as the total number of Quality and Outcomes Framework (QOF) points from 2005, obtained through the Quality Management and Analysis System (QMAS) central database. The data from QMAS also included measures of community-level deprivation using the 2004 Index of Multiple Deprivation. Descriptive statistics were obtained comparing QOF scores and deprivation scores among practices with and without a salaried GP.

Table 2. Logistic regression results of GP payment scheme 2005, presented as odds of being salaried $(n=33373)$.

\begin{tabular}{|c|c|c|}
\hline Characteristic & OR & $95 \% \mathrm{Cl}$ \\
\hline \multicolumn{3}{|l|}{ Age, years } \\
\hline$<35$ & 1.000 & Reference \\
\hline $35-44$ & 0.405 & (0.370 to 0.444$)$ \\
\hline $45-54$ & 0.179 & (0.160 to 0.200$)$ \\
\hline $55-64$ & 0.217 & (0.188 to 0.250$)$ \\
\hline$\geq 65$ & 0.639 & (0.518 to 0.787$)$ \\
\hline \multicolumn{3}{|l|}{ Sex } \\
\hline Males & 1.000 & Reference \\
\hline Females & 1.965 & (1.806 to 2.139$)$ \\
\hline \multicolumn{3}{|l|}{ Full-time/part-time } \\
\hline Full-time & 1.000 & Reference \\
\hline Part-time & 4.220 & (3.896 to 4.571 ) \\
\hline \multicolumn{3}{|l|}{ Country of qualification } \\
\hline UK & 1.000 & Reference \\
\hline EEA & 2.303 & (1.997 to 2.657 ) \\
\hline RoW & 1.542 & (1.367 to 1.740$)$ \\
\hline \multicolumn{3}{|l|}{ GMS/PMS contract } \\
\hline GMS & 1.000 & Reference \\
\hline PMS & 1.244 & (1.153 to 1.341$)$ \\
\hline \multicolumn{3}{|l|}{ UK region } \\
\hline London & 1.000 & Reference \\
\hline Northeast & 0.894 & (0.750 to 1.066$)$ \\
\hline Northwest & 0.980 & (0.859 to 1.118$)$ \\
\hline Yorkshire and Humber & 0.594 & (0.510 to 0.692$)$ \\
\hline East Midlands & 0.483 & (0.405 to 0.577$)$ \\
\hline West Midlands & 1.336 & (1.168 to 1.527$)$ \\
\hline East of England & 0.557 & (0.475 to 0.654$)$ \\
\hline Southeast & 0.997 & (0.880 to 1.130$)$ \\
\hline Southwest & 0.757 & (0.659 to 0.871$)$ \\
\hline
\end{tabular}

EEA = European Economic Area. RoW = rest of world. GMS = general medical services; $P M S=$ personal medical services. $\mathrm{OR}=$ odds ratio. $\mathrm{Cl}=$ confidence interval.

\section{RESULTS}

\section{Profiling salaried and principal GPs}

A total of 33380 GPs (excluding registrars) were recorded in the 2005 GP census, of which 29340 (88\%) were principals and 4040 (12\%) were salaried (Table 1). Salaried GPs were, on average, younger (41 versus 47 years) and more likely to be female (71\% versus $37 \%$ ). They worked fewer hours (mean 0.7 versus 0.9 full-time equivalents; $64 \%$ versus $23 \%$ part-time), and were more likely to have PMS contracts $(40 \%$ versus $33 \%)$.

Table 2 summarises the logistic regression results. Adjusting for other factors, the GPs most likely to be salaried were those under the age of 35 years, followed by those aged 65 years and older $(\mathrm{OR}=0.64 ; 95 \% \mathrm{Cl}=0.51$ to 0.79 ). Age has a nonlinear relationship with being a salaried GP; GPs aged 45-54 years were the least likely to be in salaried posts ( $\mathrm{OR}=0.18 ; 95 \% \mathrm{Cl}=0.16$ to 0.20 ). Women were almost twice as likely to be in salaried positions $(\mathrm{OR}=1.97 ; 95 \% \mathrm{Cl}=1.80$ to 2.14$)$ compared to their male counterparts. GPs working part-time were more than four times as likely to be in salaried posts as those working full-time (OR = 4.22; $95 \% \mathrm{Cl}=3.87$ to 4.60 ). There is likely to be some inter-relation between these two variables as a higher proportion of women work part-time.

GPs holding PMS contracts were more likely to be working in salaried posts than GPs with GMS contracts $(\mathrm{OR}=1.24 ; 95 \% \mathrm{Cl}=1.15$ to 1.34$)$. GPs who qualified in countries in the European Economic Area were more than twice as likely as UK-qualified GPs to be salaried (OR $=2.30 ; 95 \% \mathrm{Cl}$ $=1.99$ to 2.67); those qualifying outside the European Economic Area were also more likely to be in salaried posts $(\mathrm{OR}=1.54 ; 95 \% \mathrm{Cl}=1.36$ to 1.75) compared to UK-trained GPs. Salaried posts were more common in the West Midlands, compared with London, but less common in all other regions, particularly Yorkshire and Humber, the East Midlands, the East of England, and the Southwest.

\section{GP mobility}

In 2004/2005, 1600 of 30853 GPs (5\%) were mobile (Table 3). Of 3095 salaried GPs who appeared in the workforce in both years, 797 (26\%) had moved practice. The corresponding figure for principals was 803 of 27758 (3\%). Therefore, the unadjusted OR of moving practice for a salaried GP compared to a principal GP was $11.64(95 \% \mathrm{Cl}=$ 10.46 to 12.95). Given that particular characteristics are likely to be associated with mobility, as well as with salaried status, calculations were made for age, sex, time commitment, contract type, and country of 
qualification-adjusted OR (shown in Table 4): this OR was $8.50(95 \% \mathrm{Cl}=7.51$ to 9.63$)$. The OR is smaller in the adjusted analysis and, therefore, the relationship between mobility and salaried status can be explained to some degree by variation in the additional variables; however, a strong association between mobility and salaried status still exists. Of interest was that neither sex nor time commitment appeared to be strongly associated with mobility: their respective ORs (95\% Cls) were 1.06 (0.93 to 1.20) and 1.08 (0.95 to 1.23).

As a means of comparison, the association between mobility and salaried status was examined at two other points in time: 1996/1997 and 2000/2001 (Table 3). In 1996/1997 there were 28077 GPs who remained in the workforce; 2739 (10\%) moved practice. Salaried GPs were more mobile, with 101 of 535 (19\%) moving practice compared with 2638 of 27542 (10\%) principals. The unadjusted OR of moving practice for a salaried GP compared to a principal GP was, therefore, 2.20 $(95 \% \mathrm{Cl}=1.76$ to 2.74$)$.

In 2000/2001, 29950 GPs were included in the analysis. Overall, 3173 (11\%) GPs moved practice, again with salaried GPs being more mobile: 617 of 2230 (28\%) compared with 2556 of 27720 (9\%). Therefore, the unadjusted OR of moving practice for a salaried GP compared to a principal GP was 3.77 (95\% Cl $=3.40$ to 4.17$)$. Overall, between-practice mobility appears to be stabilising, driven by the increasing stability of GP principals. However, salaried GPs appear to be increasingly mobile in recent years, with more than one in four changing practice between 2000 and 2001 and also 2004 and 2005.

Year-to-year changes between salaried and principal status showed that few GPs change from principal to salaried and vice versa. The vast majority of GPs are principals and remain as such. The apparent steady decline in the percentage remaining as principals ( $98 \%$ to $92 \%$ to $89 \%$ ) is probably due to an increase in the number of salaried posts.

\section{Practice performance and deprivation}

A total of 8358 practices were included in the analysis of QOF scores. Table 5 shows differences in QOF scores between practices with only principals and those with at least one salaried post. QOF scores tended to be slightly higher for practices with salaried posts. The median QOF score for practices with at least one salaried post was 1017 (interquartile range [IQR] = 978 to 1039) compared with 993 for practices with principals only (IQR $=925$ to 1028). Table 5 also illustrates the 2004 Index of Multiple Deprivation scores: a higher

\begin{tabular}{|c|c|c|c|}
\hline & 1996-1997, n (\%) & 2000-2001, n (\%) & 2004-2005, n (\%) \\
\hline \multicolumn{4}{|l|}{ Mobility } \\
\hline All GPs & 28077 (100) & $29950(100)$ & $30853(100)$ \\
\hline Stable & $25338(90)$ & 26777 (89) & $29253(95)$ \\
\hline Moved & 2739 (10) & $3173(11)$ & $1600(5)$ \\
\hline Principal GPs & $27542(98)$ & 27720 (93) & $27758(90)$ \\
\hline Stable & $24904(90)$ & $25164(91)$ & $26955(97)$ \\
\hline Moved & $2638(10)$ & $2556(9)$ & $803(3)$ \\
\hline Salaried GPs & $535(2)$ & $2230(7)$ & 3095 (10) \\
\hline Stable & $434(81)$ & $1613(72)$ & $2298(74)$ \\
\hline Moved & $101(19)$ & $617(28)$ & 797 (26) \\
\hline \multicolumn{4}{|l|}{ Payment scheme } \\
\hline Remain principal & 27465 (97.82) & 27595 (92.14) & 27527 (89.22) \\
\hline Principal to salaried & $77(0.27)$ & $125(0.42)$ & $231(0.75)$ \\
\hline Salaried to principal & $105(0.37)$ & $593(1.98)$ & $522(1.69)$ \\
\hline Remain salaried & $430(1.53)$ & $1637(5.47)$ & $2573(8.34)$ \\
\hline Total & 28077 & 29950 & 30853 \\
\hline
\end{tabular}

value of which represents a more deprived community. Practices with salaried posts tended to be in slightly more affluent areas, with a median deprivation score of 17.75 (IQR $=11.48$ to 28.51) compared with 23.19 (IQR = 14.91 to 32.68$)$ for those with principals only.

\begin{tabular}{|c|c|c|}
\hline Characteristic & OR & $95 \% \mathrm{Cl}$ \\
\hline \multicolumn{3}{|l|}{ Age, years } \\
\hline$<35$ & 1.000 & Reference \\
\hline $35-44$ & 0.662 & (0.576 to 0.760$)$ \\
\hline $45-54$ & 0.442 & (0.375 to 0.522$)$ \\
\hline $55-64$ & 0.334 & (0.267 to 0.417$)$ \\
\hline$\geq 65$ & 0.431 & (0.300 to 0.619$)$ \\
\hline \multicolumn{3}{|l|}{ Sex } \\
\hline Males & 1.000 & Reference \\
\hline Females & 1.057 & (0.933 to 1.197$)$ \\
\hline \multicolumn{3}{|c|}{ Full-time/part-time } \\
\hline Full-time & 1.000 & Reference \\
\hline Part-time & 1.081 & (0.952 to 1.227$)$ \\
\hline \multicolumn{3}{|c|}{ Country of qualification } \\
\hline UK & 1.000 & Reference \\
\hline EEA & 2.001 & (1.645 to 2.433 ) \\
\hline RoW & 1.918 & (1.622 to 2.267 ) \\
\hline \multicolumn{3}{|c|}{ GMS/PMS contract } \\
\hline GMS & 1.000 & Reference \\
\hline PMS & 1.589 & (1.427 to 1.770$)$ \\
\hline \multicolumn{3}{|l|}{ GP status } \\
\hline Principal & 1.000 & Reference \\
\hline Salaried & 8.503 & (7.510 to 9.626 ) \\
\hline
\end{tabular}

EEA = European Economic Area. RoW = rest of world. GMS = general medical services; $P M S=$ personal medical services. $\mathrm{OR}=$ odds ratio. $\mathrm{Cl}=$ confidence interval. 
Table 5. Practice performance and deprivation.

\begin{tabular}{lcccccc} 
& Minimum & $25 \%$ & Median & $75 \%$ & Maximum & $n$ \\
\hline QOF score of practice & & & & & & \\
No salaried posts & 0 & 925 & 993 & 1028 & 1050 & 6103 \\
With salaried posts & 163 & 978 & 1017 & 1039 & 1050 & 2255 \\
\hline 2004 Index of Multiple Deprivation & & & & & \\
No salaried posts & 0.77 & 14.91 & 23.19 & 32.68 & 66.37 & 6103 \\
With salaried posts & 3.02 & 11.48 & 17.75 & 28.51 & 70.68 & 2254 \\
\hline
\end{tabular}

QOF = Quality and Outcomes Framework.

\section{DISCUSSION}

\section{Summary of main findings and comparison with existing literature}

Proportionately, salaried GPs are more likely to be at the extremes of working age (that is, the youngest and oldest), female, or overseas qualified, particularly from the European Economic Area. They are more likely to work part-time and hold PMS contracts. This contrasts with previous research which found younger men, those most noted for their risk-taking behaviour, predominated when salaried posts were first introduced. ${ }^{8}$ The evidence of this study supports the Williams et al prediction of an eventual salaried preference among females. ${ }^{8}$ Now, several years on, those most likely to be salaried are GPs seeking greater career flexibility (for example, part-time working), and who wish to be free from the roles and responsibilities of being a principal: including those trained abroad, women of child-bearing age, newly qualified GPs, and GPs nearing retirement.

These findings support the view that such GPs were previously under-utilised, ${ }^{9}$ and that salaried positions have enabled them to be more appropriately employed in patient care, perhaps leading to greater job satisfaction. An alternative explanation is that access to 'principal status' has become increasingly difficult. For example, practices could use salaried posts to negate the need to manage principal GPs not wishing to conform to a 'traditional' working model.

Unsurprisingly, salaried GPs are more mobile. This may be due to their shorter-term contracts and lack of long-term financial commitment to the practice as much as to personal preference (for example, those wanting mobility may prefer salaried status). ${ }^{6}$ The present data show that, overall, the number of GPs changing practice from one year to the next has almost halved. This is almost exclusively attributable to the increasing immobility of the GP principal population. Together these findings suggest that, before the popularisation of salaried posts, many principals who sought a more-flexible post had no such opportunity. However, when these opportunities arose, there was a large-scale movement to find a more suitable post. GPs who wanted to be principals remained so, whereas GPs seeking flexibility (including the expectation of being mobile) found salaried posts and continue to be mobile in a system that now facilitates this.

It was suggested that salaried posts may lead to improvements in practice performance; however, the present results are inconclusive. The data show that practices with salaried positions have only slightly higher QOF scores. Since the introduction of the QOF in 2004, GPs have surprised policy makers with their consistently high achievements on the QOF indicators. ${ }^{10}$ This lack of variability in performance limited the power of the present study to detect differences attributable to salaried status.

Originally, one objective of introducing salaried posts was to recruit GPs to deprived areas. Williams et al found limited evidence supporting this. ${ }^{8}$ The present results suggest that salaried positions now tend to be located in more affluent neighbourhoods. This may be due to the wider adoption of salaried positions by practices in more affluent neighbourhoods and/or better recruitment to those posts. An alternative explanation is that practices with higher QOF scores are located in more affluent areas. Wright et al found that practices in deprived areas tended to have markedly lower QOF scores than affluent practices, ${ }^{11}$ although Doran et al found the effects of deprivation on performance to be marginal. ${ }^{10}$ Whatever the explanation, it is clear that salaried GPs are now concentrated in affluent areas. Overall growth in the GP workforce may have increased the numbers in deprived areas, although at a lower rate than in affluent areas.

Introducing salaried posts has strongly appealed to particular subsets of GPs that did not fit well into the traditional model of principal status. Public health benefits, such as an improvement in practice performance and better recruitment into deprived areas, do not appear to have materialised. However, it is unlikely that only GPs have benefited. There may be benefits to patients of improved GP job satisfaction and workforce participation which could not be captured by this study.

\section{Strengths and limitations of the study}

This study delivers robust results as it provides an unbiased representation of the English GP population. It can probably be extrapolated to the rest of the UK. Its primary limitation is the inherent problem of cross-sectional analysis: for example, mobility analyses were performed on three crosssectional snapshots. Ideally, GPs would be followed over the entire course of study, with no gaps. 
However, changes in administrative boundaries and data collection make this very difficult.

\section{Implications for future research}

As salaried GP posts are a relatively new entity, little is known on the subject. The authors envisage that future studies will continue to investigate the impact of salaried posts on the GP workforce and, ultimately, the patient.

\section{Funding body}

This project was funded by the Department of Health, the National Primary Care Research and Development Centre, University of Manchester, and the University of California, San Francisco, School of Medicine, Office of International Programs

\section{Ethical approval}

This research is exempt from institutional and ethical review boards as the analysis is performed on de-identified public data of practitioners

\section{Competing interests}

The authors have stated that there are none

\section{Acknowledgements}

The authors would like to acknowledge and thank Diane Rittenhouse MD for her contributions to the establishment of contact between the authors, and Jack Resneck MD for his academic guidance

\section{Discuss this article}

Contribute and read comments about this article on the Discussion Forum: http://www.rcgp.org.uk/bjgp-discuss

\section{REFERENCES}

1. The Secretary of State for Health. The National Health Service (General Medical Services Contracts) Regulations 2004. Crown Copyright 2004. (SI 2004 No. 291).

www.opsi.gov.uk/si/si2004/20040291.htm (accessed 21 Nov 2007)

2. Jenkins C. Personal Medical Services pilots - new opportunities. In: Lewis R, Gillam S (eds). Transforming primary care: personal medical services in the new NHS. London: King's Fund, 1999.

3. Young R, Leese B. Recruitment and retention of general practitioners in the UK: what are the problems and solutions? Br J Gen Pract 1999; 49(447): 829-833.

4. Williams J, Petchey R, Gosden T, et al. A profile of PMS salaried GP contracts and their impact on recruitment. Fam Pract 2001; 18(3): 283-287.

5. Gosden T, Sibbald B, Williams J, et al. Paying doctors by salary: a controlled study of general practitioner behaviour in England. Health Policy 2003; 64(3): 415-423.

6. Aquino P, Kohli B. Salaried general practitioners. BMJ 2002; 325(7365): S89-90.

7. Gosden J, Williams J, Petchey R, et al. Salaried contract in UK general practice: a study of job satisfaction and stress. J Health Serv Res Policy 2002; 7(1): 26-33.

8. Williams J, Petchey R, Gosden T, et al. A profile of PMS salaried GP contracts and their impact on recruitment. Fam Pract 2001; 18: 283-287.

9. Young R, Leese B, Sibbald B. Imbalances in the GP labour market in the UK: evidence from a postal survey and interviews with GP leavers. Work, Employment and Society 2001; 15(4): 699-719.

10. Doran T, Fullwood C, Gravelle H, et al. Pay-for-performance programs in family practices in the United Kingdom. N Engl J Med 2006; 355(4): 375-384.

11. Wright J, Martin D, Cockings S, Polack C. Overall Quality of Outcomes Framework scores lower in practices in deprived areas. $\mathrm{Br} J$ Gen Pract 2006; 56(525): 277-279. 